\title{
PROBLEMS WITH THE DISPOSITIONAL TRACKING THEORY OF KNOWLEDGE
}

Ben BRONNER

\begin{abstract}
Rachel Briggs and Daniel Nolan attempt to improve on Nozick's tracking theory of knowledge by providing a modified, dispositional tracking theory. The dispositional theory, however, faces more problems than those previously noted by John Turri. First, it is not simply that satisfaction of the theory's conditions is unnecessary for knowledge - it is insufficient as well. Second, in one important respect, the dispositional theory is a step backwards relative to the original tracking theory: the original but not the dispositional theory can avoid Gettier-style counterexamples. Future attempts to improve the tracking theory would be wise to bear these problems in mind.
\end{abstract}

KEYWORDS: defining knowledge, tracking theory, safety and sensitivity, Robert Nozick, Rachel Briggs, Daniel Nolan

Rachel Briggs and Daniel Nolan amend Nozick's tracking theory of knowledge. ${ }^{1}$ Nozick claims that $S$ knows that $p$ if and only if:

(1) $p$ is true.

(2) $S$ believes that $p$.

(3) If $p$ had not been true, then $S$ would not have believed that $p$.

(4) If $p$ had been true, then $S$ would have believed that $p .^{2}$

Briggs and Nolan suggest replacing (3) and (4) with:

(3*) $S$ is disposed to not believe that $p$ in the circumstance where $p$ does not obtain.

$\left(4^{*}\right) S$ is disposed to believe that $p$ in the circumstance where $p$ obtains.

As they demonstrate, Briggs and Nolan's modified, dispositional tracking theory can deal with several counterexamples to the original tracking theory.

The dispositional tracking theory faces significant problems of its own, however. John Turri notes that satisfying the conditions of the theory is not necessary for knowledge. ${ }^{3}$ He supplies several examples where a subject has knowledge and yet does not meet condition $\left(3^{*}\right)$. Despite this problem, Turri

\footnotetext{
${ }^{1}$ Rachel Briggs and Daniel Nolan, "Mad, Bad and Dangerous to Know," Analysis 72, 2 (2012): 314-316.

2 Robert Nozick, Philosophical Explanations (Cambridge: Harvard University Press, 1981).

${ }^{3}$ John Turri, "Stumbling in Nozick's Tracks," Logos \& Episteme 3, 2 (2012): 291-293.
}

(C) LOGOS \& EPISTEME, III, 3 (2012): 505-507 


\section{Ben Bronner}

remarks that Briggs and Nolan make "modest progress along the path Nozick helped to pioneer." Certainly others will attempt to progress further along that path, and the examples Turri supplies will help in this project. Further progress may be limited, however, if nothing more is said. First, it is not simply that satisfaction of the conditions of the dispositional tracking theory is unnecessary for knowledge - it is insufficient as well. Second, in one important respect, the dispositional theory is a step backwards relative to the original tracking theory: the original but not the dispositional theory can avoid Gettier-style counterexamples.

To illustrate these problems, first consider one of the cases Briggs and Nolan describe.

DANGEROUS TO KNOW Adolf believes, having studied his symptoms and consulting with medical experts, that he has a rare brain condition that is fatal before the age of 5 years in $99.99 \%$ of cases. In fact, he is right; he's one of the one in 10,000 who have the disease but survive. However, in most nearby possible worlds here he has the disease, he dies before the age of 5 years - long before he entertains the proposition that he has the disease. Therefore, it is not true that if Adolf had had the disease, he would have believed he did. (He might well have died at 5 years.) So Adolf's belief is not safe. Nonetheless, Adolf knows he has the disease.

Though Adolf does not satisfy the conditions of the original tracking theory, he does satisfy those of the dispositional theory. After all, "Adolf has the disposition to take the word of reliable and informed authorities about the state of his health."

Now consider the following alteration of Adolf's case. Everything is as before, except: The 'medical experts' are actors and Adolf is unwittingly the subject of an elaborate hoax funded by his wealthy arch nemesis, Olaf. Not only has Olaf hired these actors, but he has tricked Adolf into thinking that the latter is manifesting symptoms of the disease in question. Unknown to Adolf, what he takes to be symptoms of the disease are in fact symptoms of the various drugs that Olaf has been slipping into Adolf's food. Unknown to both Adolf and Olaf, the former truly has the disease, but is asymptomatic.

This seems to be a Gettier-style case where Adolf has a lucky true belief but no knowledge. Yet all four of Briggs and Nolan's conditions seem to be satisfied. In particular, all of Adolf's dispositions are the same as in the original case. From Adolf's point of view, the situation is indistinguishable from that described by Briggs and Nolan. There is no difference between Briggs and Nolan's example and the modified example that could have psychologically impacted upon Adolf, changing his dispositions. It follows that satisfaction of the conditions advanced by 
Problems with the Dispositional Tracking Theory of Knowledge

Briggs and Nolan is not sufficient for knowledge. It is worth emphasizing that Nozick's tracking theory produces the correct verdict, as condition (3) is not satisfied: if Adolf had not had the disease, he still would have believed that he did. In this regard, moving from the original to the dispositional tracking theory is a step in the wrong direction - it is not simply that the dispositional theory makes "modest progress" before encountering the problem noted by Turri. Future attempts to improve the tracking theory would be wise to bear these additional problems in mind. ${ }^{4}$

${ }^{4}$ Special thanks to Dorit Ganson for helpful comments. 